\title{
A Comparison of Past and Future Leisure Activity Participation Between Spinal Cord Injured and Non-disabled Persons
}

\author{
D. W. Kennedy, PhD, ${ }^{1}$ R. W. Smith, $\mathbf{P h D}^{2}$ \\ ${ }^{1}$ Research Project Associate, Planning Studies, 404 Grange Building, The Pennsylvania \\ State University, University Park, PA 16802, USA . ${ }^{2}$ Assistant Professor, Department \\ of Leisure Studies, 203 Henderson Building South, The Pennsylvania State University, \\ University Park, PA 16802, USA.
}

\begin{abstract}
Summary
Leisure activity profiles of 81 male and 21 female SCI subjects were compared with profiles of 135 male and 151 female non-disabled individuals. These profiles, derived from the Leisure Activities Blank (McKechnie, 1985), revealed that SCI subjects had been more physically active (prior to injury) than those in a non-disabled comparison group; however, their post-injury expectations for future leisure activity involvement were considerably lower than a similar study of non-disabled individuals. These reduced expectations were found for both active and sedentary activity categories. It is suggested that awareness of pre-morbid leisure activity profiles, plus recognition that post-injury expectations for leisure activity participation are often reduced, could assist medical personnel to prescribe treatment or offer programmes that enable SCI patients to maintain their pre-morbid lifestyles and enhance future leisure activity expectations.

Key words: Spinal cord injuries; Recreation, Leisure activities; Physical disability.
\end{abstract}

The role of leisure time activity participation in psychological and physical adjustment to spinal cord injury (SCI) has received relatively little attention in the rehabilitation literature. The few studies that have examined this role, however, suggest that both the nature and amount of leisure activity involvement may be of critical importance in long term adjustment to SCI.

MacDonald, Nielson and Cameron (1987) examined the relationship between depression and activity patterns among 53 individuals with SCI living in Canadian communities. Statistically significant main effects were found for both personal activities and travel activities, and a non-significant trend was noted for social activities. With all three types of activities, the participation rates among nondepressed SCI individuals were greater than for 'mildly depressed' SCI persons. Concluding that their results have both immediate and long term implications for treatment, the authors stated, 'Some immediate implications concern the possibility

Correspondence to: R. W. Smith, Department of Leisure Studies, The Pennsylvania State University, University Park, PA, USA 16802. 
of increasing activity levels as a treatment and/or preventative intervention for depression in SCI'.

Additional support for the use of activities as a treatment modality was provided by Norris-Baker and associates (1981), who reported that the amount of independence exhibited by persons with SCI after hospital discharge was related to the number of in-hospital activities in which they participated. Other studies have indicated that the rate of rehospitalisation among SCI patients is greater for those with sedentary lifestyles (Swanson, 1976) and those who do not leave their homes at least once daily (Meyers et al., 1985). Krause and Crewe (1987) found a significant positive relationship between activity participation and long term survival of persons with SCI, concluding that 'activity level per se, rather than a mediating emotional state, enhances survival following SCI'.

Activity participation may also be related to family support, which has been cited as an important variable in adjustment to SCI (Buchanan and Nawzenski, 1987; Trieschmann, 1980). McGowan and Roth (1987) found a positive relationship between self-initiation of activities among SCI subjects and their perceptions of their families as effectively responsive and involved, effective in communication and role delineation, and healthy in family functioning.

To the extent that in-hospital and post-hospitalisation leisure activity assists physical and psychological adjustment to SCI, it is important for physicians and rehabilitation specialists to understand the nature of leisure preferences and behaviours among their SCI patients. Medical authorities need to have answers to such questions as: What pre-morbid leisure activities were important to SCI patients? What activities are perceived to be important in the future? Do past and future leisure preferences differ between SCI and non-disabled individuals? Does it matter at what stage of the rehabilitation process these preferences are determined?

The purpose of this exploratory study was to address the above issues by examining the leisure profiles of selected SCI men and women and comparing these profiles with those found among non-disabled individuals. Of particular concern in this investigation were two research questions: Do specific differences in past leisure behaviour exist between SCI individuals and those in the general population? Do SCI individuals have lower expectations than non-disabled individuals with regard to future participation in certain types of leisure activities?

\section{Methods}

\section{Subjects}

The subjects for this investigation were 102 SCI individuals ( 81 males and 21 females). Most of the subjects were inpatients at one of 14 different rehabilitation centres and/or hospitals located in various regions of the USA. Subjects ranged in age from 17 to 43 years of age, and all data were gathered within 12 months of date of injury. Summary data on 286 non-disabled individuals (135 males and 151 females) reported by McKechnie (1975) were used for comparison. 


\section{Instrumentation}

The Leisure Activities Blank (LAB) (McKechnie, 1975) was used in this investigation. This instrument requires respondents to indicate the extent of their past involvement in each of 120 leisure activities, as well as the extent of expected future participation in each activity. Details of scale construction, reliability coefficients, and validity testing can be found in McKechnie (1975). The LAB has 6 subscales (activity clusters) related to past leisure involvement and 8 subscales reflecting future leisure participation. Separate analyses were conducted for the Past and Future correlation matrices using the 'highest $r$ ' method of estimating communality. Subscales for the Past portion of the LAB include mechanical, crafts, intellectual, slow living, sports, and glamour sports. The Future portion of the LAB includes the following subscales: adventure, mechanics, crafts, easy living, intellectual, ego recognition, slow living, and clean living. Separate profiles were constructed for males and females.

\section{Data collection and analysis}

The Commission on Accreditation of Rehabilitation Facilities' (CARF) listing of accredited facilities was used to identify 40 rehabilitation centres and/or hospitals offering treatment to SCI persons throughout the USA. Letters explaining the study and requesting participation were sent to the directors of these facilities, and 22 of the original 40 facilities expressed an interest in participating. Of these, only 14 facilities were able to identify subjects with SCI during the data collection period. Therapeutic recreation personnel, or other allied health professionals, supervised the administration of all tests. A total of 102 LABs were completed.

Frequencies and percentages were used to develop individual Past and Future $\mathrm{LAB}$ profiles for each subject in this investigation. Comparisons between subjects with paraplegia and those with quadraplegia revealed no significant differences on $\mathrm{LAB}$ profiles; therefore, no distinction was made between these subgroups in this investigation. t-tests for independent samples were used to test for differences between SCI subjects and the non-disabled comparison group on each LAB subscale. The use of independent tests, although less desirable that an overall test of significance (e.g., MANOVA), was necessary because raw scores were not available for the non-disabled comparison group. The 0.05 level of significance was used for all comparisons in this investigation.

\section{Results}

\section{Males}

The t-tests between mean Past LAB scores for male SCI subjects and males in the non-disabled comparison group reflected significant differences on 3 of the 6 subscales. SCI males scored higher in the activity clusters of mechanics $(t=2 \cdot 17)$ and sports $(t=2 \cdot 72)$, but were lower on intellectual activities $(t=5 \cdot 58)$. The comparisons for all 6 Past LAB subscales are reported in Table $\bar{i}$.

Comparisons between mean Future LAB scores for male SCI subjects and nondisabled males revealed significant differences on 5 of the 8 subscales. Males with 
Table I Comparisons between SCI males $(\mathbf{n}=81)$ and non-disabled males $(\mathbf{n}=135)$ on past leisure activity participation ${ }^{1}$

\begin{tabular}{lllll}
\hline LAB & \multicolumn{1}{c}{ Group } & Mean & S.D. & t-value \\
\hline Mechanics & Non-disabled & $46 \cdot 4$ & $10 \cdot 5$ & $2 \cdot 17^{\star}$ \\
Crafts & SCI & $49 \cdot 4$ & $8 \cdot 6$ & $1 \cdot 94$ \\
& Non-disabled & $27 \cdot 2$ & $6 \cdot 3$ & $5 \cdot 58^{\star \star}$ \\
Intellectual & SCI & $25 \cdot 6$ & $5 \cdot 1$ & $0 \cdot 83$ \\
Slow living & Non-disabled & $36 \cdot 1$ & $8 \cdot 9$ & $2 \cdot 72^{\star \star}$ \\
Sports & SCI & $29 \cdot 7$ & $6 \cdot 8$ & 0 \\
& Non-disabled & $59 \cdot 5$ & $9 \cdot 8$ & $0 \cdot 10$ \\
Glamour sports & SCI & $58 \cdot 2$ & $8 \cdot 7$ & $5 \cdot 8$ \\
& Non-disabled & $28 \cdot 3$ & $7 \cdot 0$ & $7 \cdot 2$ \\
\hline
\end{tabular}

${ }^{1}$ Leisure Activities Blank (LAB)-male profile

$\star \mathrm{p}<0.05$

$\star \star \mathrm{p}<0.01$

SCI recorded lower scores than the non-disabled comparison group on adventure $(t=7 \cdot 46)$, crafts $(t=2 \cdot 96)$, intellectual $(t=6 \cdot 91)$, slow living $(t=3 \cdot 24)$, and

Table II Comparisons between SCI males $(\mathbf{n}=81)$ and non-disabled males $(\mathbf{n}=135)$ on future intentions to participate in leisure activities ${ }^{1}$

\begin{tabular}{|c|c|c|c|c|}
\hline $\begin{array}{l}\text { LAB } \\
\text { subscale }\end{array}$ & Group & Mean & S.D. & t-value \\
\hline \multirow[t]{2}{*}{ Adventure } & Non-disabled & $47 \cdot 4$ & $11 \cdot 7$ & $7 \cdot 46^{\star \star}$ \\
\hline & SCI & $36 \cdot 4$ & $8 \cdot 1$ & \\
\hline \multirow[t]{2}{*}{ Mechanics } & Non-disabled & $33 \cdot 6$ & $8 \cdot 6$ & $1 \cdot 56$ \\
\hline & SCI & $31 \cdot 9$ & $6 \cdot 1$ & \\
\hline \multirow[t]{2}{*}{ Crafts } & Non-disabled & $21 \cdot 5$ & $5 \cdot 4$ & $2 \cdot 96^{\star \star}$ \\
\hline & SCI & $19 \cdot 5$ & 3.6 & \\
\hline \multirow[t]{2}{*}{ Easy living } & Non-disabled & $24 \cdot 5$ & $5 \cdot 3$ & 0.89 \\
\hline & SCI & $23 \cdot 9$ & $3 \cdot 8$ & \\
\hline \multirow[t]{2}{*}{ Intellectual } & Non-disabled & $25 \cdot 4$ & $5 \cdot 3$ & $6 \cdot 91 \star \star$ \\
\hline & SCI & $20 \cdot 5$ & $4 \cdot 6$ & \\
\hline \multirow[t]{2}{*}{ Ego recognition } & Non-disabled & $15 \cdot 3$ & $3 \cdot 9$ & $0 \cdot 36$ \\
\hline & SCI & $15 \cdot 5$ & 3.9 & \\
\hline \multirow[t]{2}{*}{ Slow living } & Non-disabled & $40 \cdot 8$ & $4 \cdot 5$ & $3 \cdot 24^{\star \star}$ \\
\hline & SCI & $38 \cdot 8$ & $4 \cdot 2$ & \\
\hline \multirow[t]{2}{*}{ Clean living } & Non-disabled & $20 \cdot 8$ & $5 \cdot 4$ & $3 \cdot 14^{\star \star}$ \\
\hline & SCI & $18 \cdot 5$ & 4.9 & \\
\hline
\end{tabular}

${ }^{1}$ Leisure Activities Blank (LAB)-male profile

${ }^{\star \star} \mathrm{p}<0.01$

clean living $(t=3 \cdot 14)$. The results of these comparisons appear in Table II.

\section{Females}

Significant differences between mean Past LAB scores for female SCI subjects and 
non-disabled females in the comparison group were found on 2 of the 6 subscales. Scores for SCI females were higher than non-disabled females on mechanics

Table III Comparisons between SCI females $(\mathrm{n}=21)$ and non-disabled females $(\mathrm{n}=151)$ on past leisure activity participation ${ }^{1}$

\begin{tabular}{lllll}
\hline LAB & \multicolumn{1}{c}{ Group } & Mean & S.D. & t-value \\
\hline subscale & Non-disabled & $31 \cdot 3$ & $6 \cdot 0$ & $2 \cdot 79^{\star \star}$ \\
\hline Mechanics & SCI & $35 \cdot 2$ & $6 \cdot 1$ & $1 \cdot 51$ \\
& Non-disabled & $38 \cdot 1$ & $7 \cdot 5$ & \\
Crafts & SCI & $36 \cdot 1$ & $7 \cdot 3$ & $1 \cdot 81$ \\
Intellectual & Non-disabled & $32 \cdot 5$ & $7 \cdot 6$ & \\
& SCI & $29 \cdot 0$ & $6 \cdot 7$ & 0.81 \\
Slow living & Non-disabled & $60 \cdot 0$ & $8 \cdot 5$ & $2 \cdot 85 \star \star$ \\
& SCI & $59 \cdot 0$ & $9 \cdot 6$ & $1 \cdot 15$ \\
Sports & Non-disabled & $23 \cdot 9$ & $4 \cdot 4$ & \\
Glamour sports & SCI & $27 \cdot 0$ & $6 \cdot 3$ & \\
& Non-disabled & $25 \cdot 1$ & $6 \cdot 0$ & \\
\hline
\end{tabular}

${ }^{1}$ Leisure Activities Blank (LAB)-female profile

$\star \star \mathrm{p}<0.01$

$(\mathrm{t}=2 \cdot 79)$ and sports $(\mathrm{t}=2 \cdot 85)$. These results are presented in Table III.

The t-tests between mean Future LAB (female profile) scores for female SCI subjects and non-disabled females revealed differences on 3 of the 8 subscales. Females with SCI scored lower than non-disabled females on adventure $(t=2 \cdot 08)$, crafts $(t=2 \cdot 25)$ and sports $(t=2 \cdot 52)$. The results of these comparisons are reported in Table IV.

Table IV Comparisons between SCI females $(\mathrm{n}=21)$ and non-disabled females $(\mathrm{n}=15 \mathrm{l})$ on future intentions to participate in leisure activities ${ }^{1}$

\begin{tabular}{|c|c|c|c|c|}
\hline $\begin{array}{l}\text { LAB } \\
\text { subscale }\end{array}$ & Group & Mean & S.D. & t-value \\
\hline \multirow[t]{2}{*}{ Adventure } & Non-disabled & $40 \cdot 9$ & $11 \cdot 6$ & $2 \cdot 08^{\star}$ \\
\hline & SCI & $35 \cdot 5$ & $7 \cdot 1$ & \\
\hline \multirow[t]{2}{*}{ Mechanics } & Non-disabled & $24 \cdot 8$ & $5 \cdot 6$ & $0 \cdot 31$ \\
\hline & SCI & $24 \cdot 4$ & $4 \cdot 4$ & \\
\hline \multirow[t]{2}{*}{ Crafts } & Non-disabled & $29 \cdot 8$ & $6 \cdot 6$ & $2 \cdot 25^{\star}$ \\
\hline & SCI & $19 \cdot 5$ & $3 \cdot 6$ & \\
\hline \multirow[t]{2}{*}{ Easy living } & Non-disabled & $23 \cdot 2$ & $5 \cdot 7$ & 0.62 \\
\hline & SCI & $24 \cdot 0$ & $4 \cdot 4$ & \\
\hline \multirow[t]{2}{*}{ Intellectual } & Non-disabled & $24 \cdot 4$ & $6 \cdot 3$ & $2 \cdot 52^{\star}$ \\
\hline & SCI & $20 \cdot 8$ & $4 \cdot 6$ & \\
\hline \multirow[t]{2}{*}{ Ego recognition } & Non-disabled & $13 \cdot 8$ & $3 \cdot 6$ & $0 \cdot 12$ \\
\hline & SCI & $13 \cdot 9$ & $3 \cdot 0$ & \\
\hline \multirow[t]{2}{*}{ Slow living } & Non-disabled & $41 \cdot 8$ & $5 \cdot 3$ & 0.51 \\
\hline & SCI & $41 \cdot 2$ & $3 \cdot 2$ & \\
\hline \multirow[t]{2}{*}{ Clean living } & Non-disabled & $20 \cdot 9$ & $5 \cdot 1$ & $0 \cdot 17$ \\
\hline & SCI & $21 \cdot 9$ & $4 \cdot 9$ & \\
\hline
\end{tabular}

${ }^{1}$ Leisure Activities Blank (LAB)-female profile

$\star \mathrm{p}<0.05$ 


\section{Discussion}

Based upon the findings of this study, it appears that substantial differences in leisure activity profiles exist between individuals with SCI and non-disabled persons. Both males and females with SCI reported pre-morbid activity patterns that appear to be more active than the non-disabled individuals in the comparison group. Additionally, male SCI subjects reported lower participation rates for intellectual activities than the non-disabled males. While such results are not unexpected given the cause of many SCIs and the youthful nature of the SCI subjects in this investigation, they do underscore the importance that active leisure participation has held in the recent past for many SCI patients.

When future activity profiles are examined, a clear picture of lower expectations among SCI individuals emerges. Although their past activity patterns reflected higher participation rates in active leisure activities, both male and female SCI subjects anticipated less future involvement in adventure-related activities than the non-disabled subjects. Interestingly, this anticipation of less involvement among both male and female SCI subjects was also found for crafts and intellectual activities. Male SCI subjects also anticipated less involvement in slow living and clean living activities. These results indicate that SCI patients who have been injured less than 1 year have lower expectations for both active and sedentary leisure activities when compared to non-disabled individuals.

The results of this investigation may help to explain why the studies cited earlier have found such variables as depression, family dysfunction, rehospitalisation, and death rates to be negatively related to in-hospital and post-hospitalisation activity patterns. Prior to SCI, the subjects in this study were more active than those in a non-disabled comparison group, yet their post-injury expectations for future leisure activity involvement were considerably lower than the same non-disabled individuals. Perhaps in-hospital and post-hospitalisation activity participation demonstrates to the SCI individual that he or she can maintain previously established activity patterns. In other words, the more active a person with SCI remains, the less the perceived discrepancy between his or her present and former self.

The differences found in leisure profiles between SCI and non-disabled subjects suggests that norms established for the general population may not be appropriate for use with persons who have physical disabilities; rather, separate normreferenced testing may be required for different disability groups. The finding of this investigation may provide a useful start toward constructing an appropriate leisure profile for individuals with SCI.

This study has implications for physicians and allied health professionals who work with SCI patients in rehabilitation settings. Awareness of pre-morbid leisure activity profiles, plus recognition that post-injury expectations for leisure activity participation are often reduced, could enable medical personnel to prescribe treatment or offer programmes that enable the SCI patient to maintain their premorbid lifestyles and enhance future leisure activity expectations. In conjunction with conventional treatment methods, such attention to leisure activities might help to reduce clinical depression, lessen rehospitalisation, improve family interaction, and prolong life expectancy among SCI patients. 


\section{References}

BuchanAN LE, NAwZENSKI, DA 1987 Spinal cord injury: Concepts and management approaches, Williams \& Wilkins, Maryland.

KraUSE JS, CrEwE NM 1987 Prediction of long-term survival of persons with spinal cord injury: An 11-year prospective study. Rehabilitation Psychology 32:203-213.

Macdonald MR, Nielson, WR, Cameron, MGP 1987 Depression and activity patterns of spinal cord injured persons living in the community. Archives of Physical Medicine and Rehabilitation 68:339-343.

McKechnie, GF 1975 Manual for Leisure Activities Blank. Consulting Psychologists Press, PaloAlto, California.

MEYERS AR, FELtin M, MASTER RJ et al. 1985 Rehospitalization and spinal cord injury: Crosssectional survey of adults living independently. Archives of Physical Medicine and Rehabilitation 66:704-708.

MCGowAN MB, Roth S 1987 Family functioning and functional independence in spinal cord injury adjustment. Paraplegia 25:357-365.

NORRIS-BAKER C, STEPHENS MAP et al. 1981 Patient behavior as predictor of outcomes in spinal cord injury. Archives of Physical Medicine and Rehabilitation 62:602-608.

SwANSON E 1976 The relationship between locus-of-control expectancy and successful rehabilitation of the spinal cord injured. Unpublished doctoral dissertation, Arizona State University, Tempe, USA.

Trieschmann RB 1980 Spinal cord injuries: Psychological, Social and Vocational Adjustment. Pergamon Press, New York. 